\title{
Being perceived as a knowledge sender or knowledge receiver: A multistudy investigation of the effect of age on knowledge transfer
}

\author{
Anne Burmeister ${ }^{1} *$ (D), Ulrike Fasbender ${ }^{2}$ and \\ Jürgen Deller ${ }^{3,4}$ \\ 'University of Bern, Switzerland \\ ${ }^{2}$ Justus-Liebig-University Giessen, Germany \\ ${ }^{3}$ Leuphana University of Lueneburg, Germany \\ ${ }^{4}$ Silver Workers Research Institute, Berlin, Germany
}

\begin{abstract}
As a result of demographic changes, workforces are becoming older and more age diverse. While interactions between workers from different age groups can provide opportunities for mutual learning through bidirectional knowledge transfer, research has yet to investigate how age influences knowledge transfer between age-diverse colleagues. Building on the organizational theory of age effects, we conducted two studies to examine how age influenced the roles assigned to individuals in knowledge transfer processes, that is, whether they were perceived as knowledge senders or knowledge recipients. In Study I, we used an experimental vignette design with 450 employees to assess how age affected perceived ability and motivation to share and receive knowledge. Further, we tested the extent to which trustworthiness moderated these relationships. In Study 2, we extended these findings using a dyadic research design with data from 53 age-diverse knowledge transfer dyads. We examined through which mechanisms the age of one's colleague affected one's knowledge transfer behaviour. We found that the age of one's colleague had a positive effect on one's knowledge receiving behaviour and a negative effect on one's knowledge sharing behaviour. Further, perceived ability to receive knowledge and perceived motivation to share knowledge mediated these effects.
\end{abstract}

Workforces in industrialized economies are becoming ever more age diverse due to demographic changes (Rudolph \& Zacher, 2015). Age diversity can be useful for organizations when employees of different ages make their diverse and valuable knowledge available to others within the organization (Burmeister \& Deller, 2016). In particular, older and younger employees can benefit from each other's knowledge (i.e., enriched information recorded in an individual's memory; Bender \& Fish, 2000) because they often have distinct and non-redundant experiences. For example, younger employees might demonstrate to older colleagues how to use a new computer software, while older employees can share and discuss their company-specific knowledge, and might invite younger colleagues to imitate the way they get things done in the company (Gerpott, Lehmann-Willenbrock, \& Voelpel, 2017).

*Correspondence should be addressed to Anne Burmeister, University of Bern, Fabrikstrasse 8, 30I 2 Bern, Switzerland (email: anne.burmeister@psy.unibe.ch). 
Yet, bidirectional knowledge transfer (i.e., the sharing and receiving of knowledge between two employees) is a difficult process that requires investments of time and effort from both actors (Szulanski, 1996). In the context of age-diverse workforces, it can be further inhibited by age effects resulting from age norms. Age norms are 'widely shared judgments of the standard or typical age of individuals holding a role or status' (Lawrence, 1988, p. 310). The applicability of this perspective to work contexts remains untested to date (Rudolph \& Zacher, 2015). However, initial empirical evidence suggests that older workers seem predestined to be perceived as knowledge senders (Voelpel, Sauer, \& Biemann, 2012), while younger workers seem to be expected to occupy the role of knowledge recipients (Deal, Altman, \& Rogelberg, 2010). These perceptions seem to operate regardless of individuals' tenure, experience, and expertise (Dunham \& Burt, 2011), which might be indicative of normative expectations about the roles that individuals should hold at certain ages when engaging in knowledge transfer.

However, this one-directional conceptualization of knowledge transfer, in which older workers only occupy the role of knowledge senders and younger workers only occupy the role of knowledge recipients, has two main limitations. First, younger workers possess valuable knowledge that, only when shared with other organizational members, can foster individual and organizational productivity (Gerpott et al., 2017; Harvey, 2012; Tempest, 2003). For example, younger workers can contribute their latest scientific and technical knowledge (Gerpott et al., 2017), and they can function as catalysts that unlock the knowledge base of older workers through questioning and discussion (Tempest, 2003). Second, older workers, who are only required to share their knowledge but are not expected to seek knowledge, may be deprived of the opportunity to learn and further develop their career, a factor that has been shown to be important for their motivation to continue working (Kooij, de Lange, Jansen, \& Dikkers, 2008). Consequently, while it seems appealing to conceptualize older workers as knowledge senders and younger workers as knowledge seekers, organizations that only facilitate one-directional knowledge transfer between older and younger workers may not use the full potential of their age-diverse workforces.

In this study, we draw on the organizational theory of age effects (Lawrence, 1987), to examine how age elicits normative expectations about prescribed roles in knowledge transfer processes, and whether these expectations potentially influence employees' actual knowledge transfer behaviour. In addition, we explore whether perceived trustworthiness, the evaluation of others' competence, benevolence, and integrity (Mayer, Davis, \& Schoorman, 1995), can shape how age affects these normative expectations. In Study 1, we test whether age influences perceived ability (i.e., the 'can do' component of behaviour) and perceived motivation (i.e., the 'will do' component of behaviour) to share and receive knowledge using an experimental vignette design. We focus on perceived ability and motivation because these individual characteristics are central for predicting knowledge transfer (Reinholt, Pedersen, \& Foss, 2011). Further, we examine the moderating role of trustworthiness on these relationships and argue that because trustworthiness can reduce the risks and uncertainties associated with sharing and receiving knowledge (Levin, Whitener, \& Cross, 2006), it can potentially override the normative expectations caused by age. In Study 2, we investigate whether and how the age of one colleague can affect the actual knowledge transfer behaviour of another colleague using a dyadic design involving matched pairs of older and younger employees. Specifically, we develop perceived ability and motivation as mediators to explain why the age of one's colleague affects one's knowledge transfer behaviour. As a result, we aim to 
generate a first understanding about the mechanisms through which age norms can affect knowledge transfer behaviour at work.

With this research, we aim to make four main contributions. First, by examining the effects of age on knowledge transfer as a relevant organizational outcome, we contribute to the growing body of research that examines how organizations can respond to the challenges and opportunities created by demographic changes (Henry, Zacher, \& Desmette, 2015; Hertel \& Zacher, 2015). Second, we aim to contribute to the research on the organizational theory of age effects by developing perceived ability and motivation as two relevant mediators that explain why age elicits its effects on knowledge transfer behaviour at work. From a practical perspective, such findings are relevant because organizations cannot change employees' age but they may be able to influence employees' perceived ability and motivation to share and receive knowledge. Third, our analysis regarding the role of trustworthiness as a buffer enables a more differentiated analysis of age effects. As individual differences are larger within rather than between age groups (Staudinger, 2015; Zacher, 2015), the analysis of individual characteristics is necessary to understand differential effects among workers of the same age. Fourth, we disentangle knowledge transfer into its constituting parts: knowledge sharing and knowledge receiving (e.g., Reinholt et al., 2011). This established distinction (Davenport \& Prusak, 1998) is rarely applied in empirical studies (Wilkesmann, Wilkesmann, \& Virgillito, 2009), but it is relevant to identify the differential effects of age on knowledge transfer behaviour.

\section{Theoretical background}

The organizational theory of age effects and knowledge transfer behaviour at work

The organizational theory of age effects by Lawrence (1987) explains how age and age distributions in organizations influence age norms, which then lead to age effects that refer to behavioural responses that can result from violations of age norms. In general, people develop normative conceptions and socially constructed expectations about individual developmental trajectories (Heckhausen \& Krueger, 1993), based on chronological age as a reference system (i.e., a person's calendar age; Kooij et al., 2008). In a work context, age norms can predict behavioural responses of individuals concerning the enactment of certain roles within organizations, which may or may not be in line with widely shared expectations of the appropriate ages for these roles (Finkelstein, Allen, \& Rhoton, 2003; Lawrence, 1987).

The conceptualization of age norms and age effects in the organizational theory of age effects is particularly useful to study knowledge transfer as an interactive and dyadic process, because it emphasizes the behavioural reactions (here: knowledge transfer) of employees in response to the age of other employees with whom they interact. Knowledge transfer consists of knowledge sharing behaviour on the one hand and knowledge-seeking behaviour on the other hand, and it takes place when employees, who are willing and able to share and seek knowledge, transfer their knowledge in a dyadic and interactive process (Reinholt et al., 2011; Szulanski, 1996). This dyadic knowledge transfer process may be affected by behavioural reactions of employees in response to the age of the employee with whom they interact, and by the role, this employee occupies in the knowledge transfer process. Importantly, the organizational theory of age effects suggests that employees can occupy roles during knowledge transfer that may or may not be in line with normative expectations of 
individual development over the lifespan. To that end, we propose that employees perceive the role of knowledge sending as being in line with higher age, while they perceive the role of knowledge receiving as being in line with lower age, which is outlined in more detail in our hypotheses development.

\section{HYPOTHESES DEVELOPMENT: STUDY I}

The effect of age on perceived ability and motivation to share and receive knowledge First, we predict that age is positively associated with perceived ability and motivation to share knowledge because of age norms that reflect the expectation that age and expertise are positively related, such that older workers should be in a position to share their valuable knowledge with others. Research has shown that employees seem to hold positive expectations with regard to older workers' knowledge, expertise, and wisdom (McGregor, 2001; Weiss \& Lang, 2012) such that older workers were perceived as 'go-to' people who are motivated to provide useful work-related advice (Dunham \& Burt, 2011; Finkelstein, Allen et al., 2003). In addition, as younger workers tend to demonstrate higher growth-related motives, and older workers tend to show higher generativityrelated motives (Erikson, 1963; Kooij, de Lange, Jansen, Kanfer, \& Dikkers, 2011), younger workers may be perceived as able and willing to receive knowledge to develop themselves, while older workers may be recognized as the ideal knowledge senders, who aim to benefit others (Deal et al., 2010; Voelpel et al., 2012). As such, older workers who occupy the role of knowledge senders and younger workers who occupy the role of knowledge recipients may be perceived as in sync with normative expectations. Taken together, we hypothesize:

Hypothesis 1: Age is positively associated with perceived (a) ability and (b) motivation to share knowledge.

Second, we predict that age is negatively related to perceived ability and motivation to receive knowledge because of age norms that reflect the expectation that age and expertise are positively related such that only younger workers should receive knowledge from others. In support of our proposition, older workers have seemed to internalize the prevailing notion of being knowledgeable, which makes it less acceptable for them to seek out information and support from others without violating existing age norms (Finkelstein, Kulas, \& Dages, 2003; Finkelstein, Allen, et al., 2003). To that end, research has shown that older workers tend to report a lower need for developmental support (Finkelstein, Allen, et al., 2003) and often demonstrate less information-seeking behaviour (Finkelstein, Kulas et al., 2003). In addition, younger workers are likely to assume the role of protégés in mentoring relationships who receive knowledge and benefit from the knowledge and experience of typically older colleagues (Finkelstein, Allen, et al., 2003). As such, younger workers can be seen as inexperienced and immature, which infers they lack the necessary experience to accumulate valuable knowledge that could be useful for other employees within the organization (Deal et al., 2010; Nadler, Morr, \& Naumann, 2017; North \& Fiske, 2012). These findings suggest that younger workers are more likely to be perceived as knowledge recipients compared to older workers. Thus, we hypothesize:

Hypothesis 2: Age is negatively associated with perceived (a) ability and (b) motivation to receive knowledge. 


\section{Can trustworthiness override effects of age norms on knowledge transfer?}

Knowledge transfer involves some degree of uncertainty about whether colleagues are able and motivated to share or receive knowledge, which highlights the importance of trustworthiness in the context of knowledge transfer (Andrews \& Delahaye, 2000; Levin et al., 2006; Szulanski, Cappetta, \& Jensen, 2004). Trustworthiness is defined as a continuum of individuals' competence, benevolence, and integrity that might lead to trust if evaluated favourably in a given situation (Mayer et al., 1995). In general, colleagues rely on each other based on the expectation that the other party will act in a trustworthy manner (Thielmann, 2016; Thielmann \& Hilbig, 2015). From previous research, we already know that trustworthiness can have positive effects on knowledge transfer (van Acker, Vermeulen, Kreijns, Lutgerink, \& van Buuren, 2014; Pinjani \& Palvia, 2013). Specifically, trustworthiness can reduce the risks associated with sharing and receiving knowledge, such as admitting knowledge gaps and being perceived as less knowledgeable by colleagues (Bender \& Fish, 2000; Borgatti \& Cross, 2003).

In this study, we extend previous research by highlighting the moderating role of trustworthiness. In particular, we investigate how trustworthiness can shape the strength of the relationships between age and perceived ability and motivation to share and to receive knowledge. Based on the notion that trustworthiness can reduce risks associated with sharing and receiving knowledge (Bender \& Fish, 2000; Borgatti \& Cross, 2003), we argue that high trustworthiness can inhibit the interpersonal effects of age norms on knowledge transfer behaviour. Diversity researchers have distinguished between surface (i.e., visible differences) and deep-level (i.e., non-visible differences) characteristics at work. Research revealed that surface characteristics (e.g., someone's age) can be informative if information about deep-level characteristics (e.g., someone's trustworthiness) is not present or unsatisfactory because people use them as a proxy for such deeplevel characteristics (Phillips \& Loyd, 2006). Pinjani and Palvia (2013), for example, have shown that deep-level characteristics have a stronger impact on knowledge sharing behaviour than surface characteristics.

Trustworthiness as a deep-level characteristic lies on a continuum ranging from lower to higher levels of trustworthiness, and higher levels of trustworthiness are thought to have a stronger impact on normative expectations in a work context (Colquitt, Scott, \& LePine, 2007). To that end, high levels of trustworthiness may compensate for negative age norms (either towards the younger or the older age group), whereas low levels of trustworthiness may substantiate existing age norms. In situations of insufficient or unsatisfactory information about others' trustworthiness, people tend to use other information, such as age, as cues to understand whether colleagues are able and motivated to share or receive knowledge at work (i.e., interpersonal effects of age norms). Yet, information about someone's trustworthiness (if positively evaluated) can partially override age norms and role expectations because trustworthiness reduces risks associated with knowledge transfer. Specifically, if trustworthiness is high, age norms are less important in evaluating others' ability and motivation during the knowledge transfer process. Put differently, we assume that trustworthiness can buffer the positive effects of age on perceived ability and motivation to receive knowledge and the negative effects on perceived ability and motivation to share knowledge. Thus, we hypothesize:

Hypothesis 3: Trustworthiness moderates the relationships between age and perceived (a) ability and (b) motivation to share, and perceived (c) ability, and (d) motivation to receive knowledge. More specifically, when trustworthiness is high, the impact of age on 
these knowledge receiving and sharing perceptions will be lower than when trustworthiness is low.

Further, as trustworthiness is often described along three dimensions, namely competence, benevolence, and integrity (Mayer et al., 1995), we additionally explore whether any of the three dimensions may be more relevant than the other two dimensions in influencing knowledge transfer. According to Mayer et al. (1995), competence describes the evaluation of an employee as active, capable, and successful in a specific work domain. Furthermore, benevolence refers to the evaluation of an employee as concerned about others, as well as helpful and supportive in situations even if the employee does not foresee an egocentric profit. Finally, integrity describes the evaluation of an employee as fair, upright, and principled. Even though the three dimensions are often interrelated with each other, 'they are separable' (Mayer et al., 1995, p. 720), and, thus, may have differential effects on the relationships between age and perceived ability and motivation to share and to receive knowledge. Thus, we pose the following research question:

Research Question 1: To what extent does the trustworthiness dimension (i.e., competence, benevolence, integrity) influence the relationships between age and perceived ability and motivation to share and receive knowledge differently?

\section{Method}

\section{Participants and procedure}

We generated a student-recruited sample to test our hypotheses, following the recommendations by Wheeler, Shanine, Leon, and Whitman (2014). We instructed eight students to generate a list of email addresses of German employees who were at least 18 years old and worked for at least $20 \mathrm{hrs}$ per week in a diverse range of industries. We monitored their progress closely and discussed potential questions in a weekly meeting. We then invited the 849 employees that were on the list to take part in our study. In total, 450 participants completed the study, yielding a response rate of 53.0\%. Participants worked in different industries ranging from finance and insurance to manufacturing, retail trade, and transportation and warehousing. On average, they were 38.39 years old $(S D=14.03)$, ranging from 19 to 66 years, and 57.2\% were female. Of the participants, $62.2 \%$ held a degree in higher education, and $20.2 \%$ indicated that they were currently enrolled as students. About one-third of participants (31.7\%) had managerial responsibility at work. As compared to the German working population (German Federal Statistics Office, 2016), our sample was slightly younger and contained a higher percentage of women.

\section{Study design}

We designed an experimental vignette study to examine the effect of workers' age, level of trustworthiness, and trustworthiness dimension on perceived ability and motivation to share as well as perceived ability and motivation to receive knowledge. Experimental vignette methodology has been described as a systematic approach in achieving both internal and external validity (Aguinis \& Bradley, 2014). The current vignette study consisted of a 2 (age: old vs. young) $\times 3$ (trustworthiness dimension: competence vs. benevolence vs. integrity) $\times 2$ (level of trustworthiness: low vs. high) 
mixed factorial design. Age and trustworthiness dimension were within-subject factors, and level of trustworthiness was a between-subject factor, resulting in 12 vignettes. Participants were randomly assigned to one of the two level of trustworthiness conditions (high level of trustworthiness vs. low level of trustworthiness) so that each study participant received only six vignettes. We carefully constructed each vignette using a business portrait photograph and a short description of the worker's typical behaviour at work.

We manipulated three variables: age, trustworthiness dimension, and level of trustworthiness. First, we manipulated age by presenting photographs from older and younger workers. To ensure the equivalence of the photographs used to manipulate age, we conducted a pilot study with 32 participants based on a priori power analysis (calculated in $G^{*}$ Power). Participants were shown 20 different portrait photographs from old and young businessmen with the aim of obtaining three equivalent photographs for each age group (young vs. old) as study material. We asked participants to indicate the age of the businessmen as well as their attractiveness $(1=$ not at all to $5=$ extremely attractive), because physical attractiveness can bias evaluations of abilities and trustworthiness in an employment situation (e.g., Tews, Stafford, \& Zhu, 2009). Based on the results of a one-way repeated-measures ANOVA (Table 1), we selected three photographs of older businessmen that did not differ significantly with regard to age, $F(2$, $52)=0.64, p=.53$, and attractiveness, $F(2,62)=1.77, p=.18$. The older businessmen were, on average, estimated to be 54 years old. Following the same procedure, we also selected three photographs of younger businessmen that did not differ significantly with regard to age, $F(2,54)=1.94, p=.15$, and attractiveness, $F(2,62)=1.35, p=.27$. On average, the younger businessmen were estimated to be 30 years old. Second, we manipulated the trustworthiness dimension by descriptions of workers' behaviour along the dimensions of competence (i.e., competent, capable, active, successful), benevolence (i.e., friendly, concerned about others, helpful and supportive), and integrity (i.e., upright, value-driven, fair, principled). The adjectives that we used to describe each trustworthiness dimension were based on Mayer et al. (1995). Third, we manipulated level of trustworthiness by indicating the extent of workers' trustworthiness (e.g., low benevolence: 'very unfriendly person, who is seldom benevolent and supportive towards others at work'; high benevolence: 'very friendly person, who is always benevolent and supportive towards others at work').

Table I. Study I. Manipulation check: Age and attractiveness of businessmen shown in experimental vignettes

\begin{tabular}{lccccc}
\hline & \multicolumn{2}{c}{ Age } & & \multicolumn{2}{c}{ Attractiveness } \\
\cline { 2 - 3 } \cline { 5 - 6 } & $M$ & $S D$ & & & $S D$ \\
\hline Photograph old I & 53.30 & 4.44 & 2.44 & 1.01 \\
Photograph old 2 & 54.48 & 4.55 & & 2.34 & 0.94 \\
Photograph old 3 & 54.33 & 5.71 & & 2.09 & 0.93 \\
Photograph young 1 & 29.24 & 3.97 & 3.13 & 0.98 \\
Photograph young 2 & 29.10 & 3.82 & & 3.38 & 0.98 \\
Photograph young 3 & 30.52 & 3.52 & 3.38 & 1.01 \\
\hline
\end{tabular}

Note.. $N=29-32$. 


\section{Measures}

If not indicated otherwise, participants provided their responses on a seven-point Likerttype scale $(1=$ totally disagree, $7=$ totally agree $)$.

\section{Perceived ability to share knowledge}

We measured ability to share knowledge using the five-item scale developed by Burmeister, Lazarova, and Deller (2017). ${ }^{1}$ A sample item is 'The employee is able to explain the usefulness of his knowledge to others'. Cronbach's $\alpha$ was .94.

\section{Perceived motivation to share knowledge}

We measured motivation to share with the six-item scale developed by Burmeister et al. (2017). ${ }^{1}$ A sample item is 'The employee is not afraid of losing power when transferring his knowledge to others'. Cronbach's $\alpha$ was .92.

\section{Perceived ability to receive knowledge}

We measured ability to receive knowledge using the five-item scale developed by Burmeister et al. (2017). ${ }^{1}$ A sample item is 'The employee has the ability to acquire knowledge from others'. Cronbach's $\alpha$ was .93.

\section{Perceived motivation to receive knowledge}

We measured motivation to receive knowledge with the six-item scale developed by Burmeister et al. (2017). ${ }^{1}$ A sample item is 'The employee actively seeks out knowledge from others'. Cronbach's $\alpha$ was .91.

\section{Control variables}

As the outcome variables may be affected by participants' age, sex, and education (Martins $\&$ Meyer, 2012), we included these variables as covariates in the analyses. In addition, we controlled for participants' managerial responsibility and student status to provide a more robust examination of the hypothesized relationships.

\section{Data analysis}

Our data had a nested structure because each participant had to evaluate six vignettes, which resulted in 2,189 data patterns nested in 379 individuals (without missing values). To test our hypotheses, we conducted multilevel analysis in Mplus 7.31 (Muthén \& Muthén, 2015), to be able to analyse both levels simultaneously (Aguinis \& Bradley, 2014; Aguinis, Gottfredson, \& Culpepper, 2013). In preparation for the analysis, workers' age (young vs. old) and trustworthiness dimension (i.e., competence vs. benevolence or

\footnotetext{
' The validity of the scales has been verified in two studies. First, the content validity of the items has been verified using the content adequacy assessment method introduced by Schriesheim, Powers, Scandura, Gardiner, \& Lankau (1 993) with a sample of $\mathrm{N}=72$ German undergraduate psychology students. Second, the construct validity (especially the discriminant validity) and the criterion-related validity of the scales have been verified using confirmatory factor analysis and regression analysis in a dyadic sample of $\mathrm{N}=101$ knowledge transfer dyads working in Germany. More information is available from the authors upon request.
} 
integrity) were group mean-centred, whereas control variables (i.e., participants' age, sex, education, student status, and managerial responsibility) and level of trustworthiness (high vs. low) were grand-mean-centred.

We conducted the multilevel analysis in four steps. First, we estimated a null model (Model 1) and found that a substantial amount of variance was explained by person-level variables (ability to transfer knowledge: ICC $=.56$; motivation to transfer knowledge: ICC $=.55$; ability to receive knowledge: ICC $=.50$; motivation to receive knowledge: ICC $=.57$ ). Second, we included control variables (i.e., participants' age, sex, education, student status, and managerial responsibility) and trustworthiness dimension (Model 2). Third, we included direct effects for workers' age (young vs. old) and level of trustworthiness (low vs. high; Model 3). Fourth, we added the cross-level interaction effects of level of trustworthiness on the relationships between workers' age and perceived ability and motivation to share and to receive knowledge (Model 4). Likelihoodratio tests revealed that the hypothesized Model 4 fit the data significantly better than Model $1(\Delta-2 \log$ likelihood $=4,163.14, p<.01, \Delta d f=8)$, Model $2(\Delta-2 \log$ likelihood $=1,336.74, p<.01, \Delta d f=3)$, and Model $3(\Delta-2 \log$ likelihood $=307.07$, $p<.01, \Delta d f=1$ ). Figure 1 depicts the multilevel model.

\section{Results}

\section{Preliminary analysis}

Prior to testing our hypotheses, we performed manipulation checks for level and dimension of trustworthiness. With regard to the between-subject manipulation level of trustworthiness, participants were asked: 'In general, how trustworthy do you think this employee is in a professional context?' As indicated in Table 2, the results of the repeatedmeasures ANOVA revealed a significant main effect for level of trustworthiness, low: $M=2.40, S D=0.53$; high: $M=3.92, S D=0.53 ; F(1,399)=825.91, p<.01$, thus supporting the successful manipulation of level of trustworthiness. Manipulation checks for trustworthiness dimension as a within-subject factor showed mixed findings

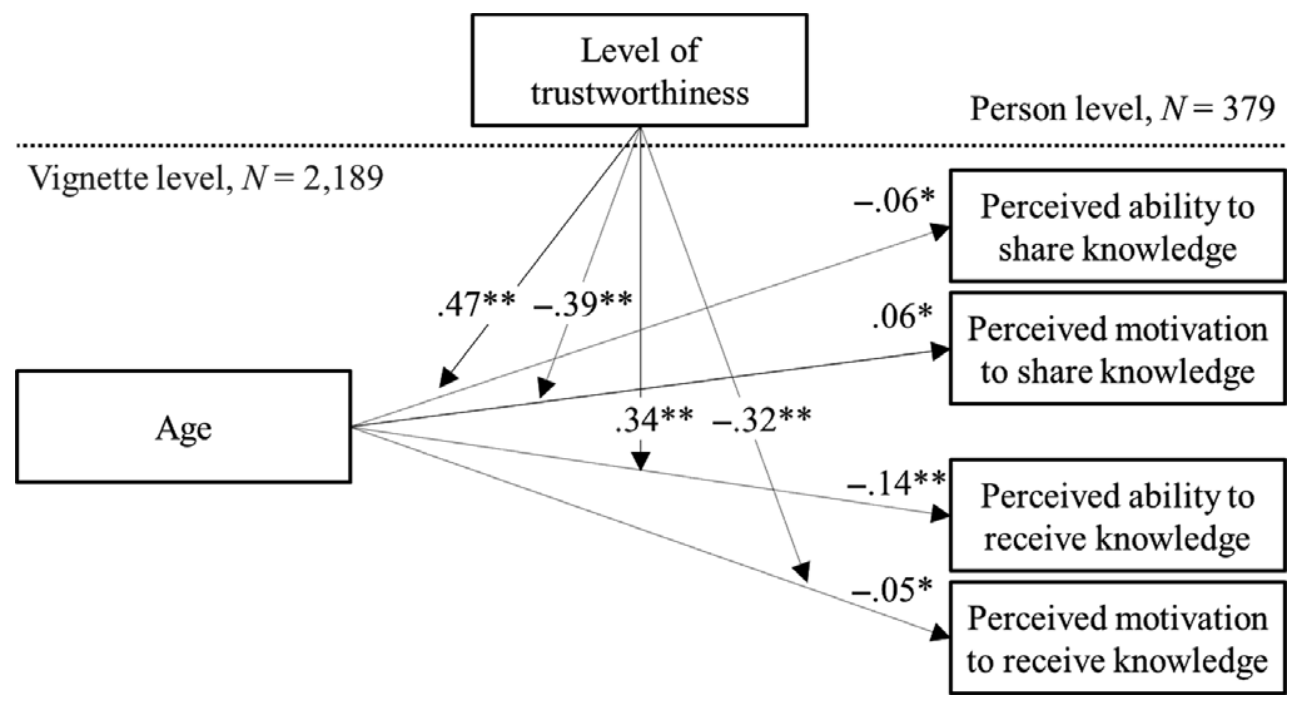

Figure I. Study I: Results of multilevel modelling. 
Table 2. Study I. Manipulation check: Level of trustworthiness across age and trustworthiness dimension

\begin{tabular}{|c|c|c|c|c|}
\hline \multirow[b]{3}{*}{ Within } & \multicolumn{4}{|c|}{ Between } \\
\hline & \multicolumn{2}{|c|}{ Low trustworthiness } & \multicolumn{2}{|c|}{ High trustworthiness } \\
\hline & M & $S D$ & $M$ & $S D$ \\
\hline \multicolumn{5}{|l|}{ Young } \\
\hline Competence & 2.21 & 0.79 & 3.83 & 0.79 \\
\hline Benevolence & 2.26 & 0.87 & 4.14 & 0.79 \\
\hline Integrity & 2.09 & 0.78 & 3.90 & 0.87 \\
\hline \multicolumn{5}{|l|}{ Old } \\
\hline Competence & 3.01 & 0.77 & 3.88 & 0.74 \\
\hline Benevolence & 2.09 & 0.78 & 3.98 & 0.79 \\
\hline Integrity & 2.83 & 0.80 & 3.72 & 0.80 \\
\hline
\end{tabular}

Note. $N=203$ for low trustworthiness; $N=198$ for high trustworthiness.

(Appendix A). Therefore, we did not use it as an independent variable, but kept it as a control variable in the further analyses. Consequently, we were unable to explore Research Question 1.

\section{Hypothesis testing}

Hypotheses 1 and 2 addressed the relationships between workers' age and perceived ability and motivation to share and receive knowledge. Contrary to our Hypothesis 1a, older workers were less likely than younger to be perceived as being able to share knowledge. However, older workers were more likely than younger workers to be perceived as being motivated to share knowledge, thus, supporting Hypothesis $1 \mathrm{~b}$. Further, we found that older workers were less likely than younger workers to be perceived as able and motivated to receive knowledge, supporting both Hypotheses $2 \mathrm{a}$ and $2 \mathrm{~b}$.

Hypothesis 3 addressed the moderating role of level of trustworthiness on the relationships of workers' age and being perceived as able and motivated to share and to receive knowledge. As can be seen in Figure 2, trustworthiness had a positive main effect on the four outcome variables, namely on (1) ability to share knowledge $(B=1.05$, $p<.01)$, (2) motivation to share knowledge $(B=1.08, p<.01)$, (3) ability to receive knowledge $(B=0.80, p<.01)$, and (4) motivation to receive knowledge $(B=0.90$, $p<.01)$.

Regarding Hypothesis $3 a$, we found that trustworthiness moderated the relationship between workers' age and perceived ability to share knowledge. Yet, although we hypothesized that trustworthiness would alter the strength of the relationship, we found that trustworthiness actually changed the direction of the relationship. A simple slope analysis revealed that the negative relationship was stronger when trustworthiness was low (simple slope $=-0.30, p<.01$ ), whereas the relationship turned positive when trustworthiness was high (simple slope $=0.18, p<.01$ ). In other words, when trustworthiness was high, vignettes containing older workers were significantly rated higher than younger workers in their ability to share knowledge. However, when trustworthiness was low, the opposite effect was found. 

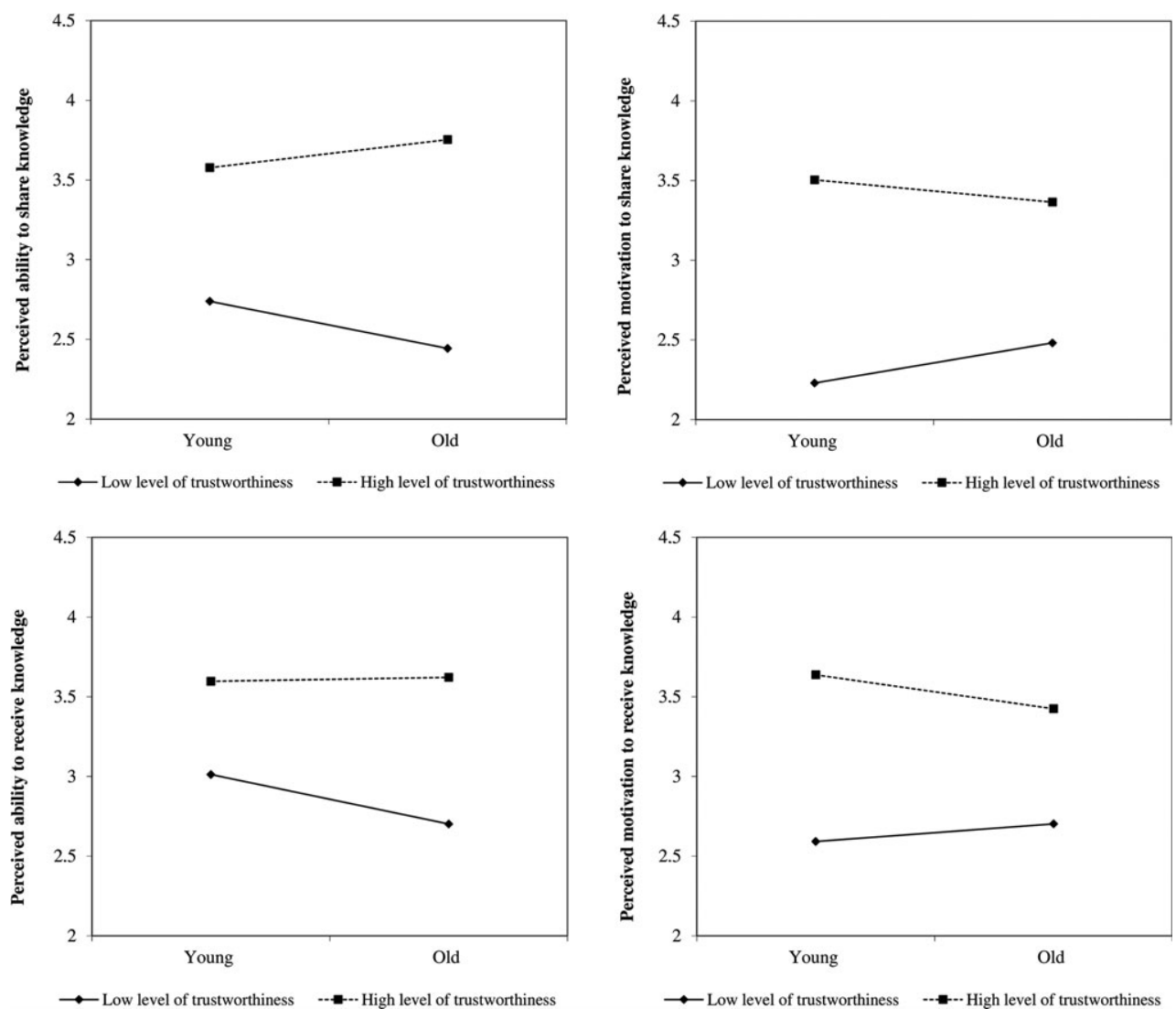

Figure 2. Study I: Interaction of age and trustworthiness.

Regarding Hypothesis 3b, we also found that trustworthiness changed the direction of the relationship between workers' age and perceived motivation to share knowledge. Specially, a simple slope analysis revealed that the positive relationship was stronger when trustworthiness was low (simple slope $=0.26, p<.01$ ), whereas the relationship turned negative when trustworthiness was high (simple slope $=-0.14, p<.01$ ). This indicates that when trustworthiness was high, vignettes containing older workers were significantly rated lower than younger workers in their motivation to share knowledge. Again, the opposite effect was found then trustworthiness was low.

In line with Hypothesis 3c, a simple slope analysis showed that the negative relationship between age and perceived ability to receive knowledge was stronger when trustworthiness was low (simple slope $=-0.31, p<.01$ ), but not significant when trustworthiness was high (simple slope $=0.04, p>.05$ ). In other words, only when trustworthiness was low, vignettes containing older workers were significantly rated lower than younger workers in their ability to receive knowledge. Yet, when trustworthiness was high, vignettes containing older workers and younger workers were equally rated in their ability to receive knowledge.

Contrary to Hypothesis $3 \mathrm{~d}$, the estimated coefficients showed that the negative relationship between workers' age and perceived motivation to receive knowledge was stronger when trustworthiness was high (simple slope $=-0.21, p<.01$ ), whereas the 
relationship turned positive when trustworthiness was low (simple slope $=0.11$, $p<.01)$. This indicates that when trustworthiness was high, vignettes containing older workers were rated significantly lower than younger workers, whereas when trustworthiness was low, vignettes containing older workers were rated significantly higher than younger workers in their perceived motivation to receive knowledge.

\section{Discussion}

The findings of Study 1 shed light on different age norms concerning the ability and motivation to share and receive knowledge by indicating that age has an impact on perceived ability and motivation to share and receive knowledge. Our finding that age is positively associated with perceived motivation to share knowledge (Hypothesis 1b), but not with perceived ability to share knowledge (Hypothesis 1a), suggests that rather than being the go-to people, older workers are perceived as employees who see themselves as the go-to people based on their need to share work experiences with their younger colleagues. People's scepticism about older workers' ability to share knowledge might be explained by negative age stereotypes, which portray older workers as less competent due to declining mental capacities (Cuddy, Norton, \& Fiske, 2005). Our findings that younger workers were more likely than older workers to be perceived as able and motivated to receive knowledge (Hypotheses $2 \mathrm{a}$ and $2 \mathrm{~b}$ ) support the existence of age norms that portray younger workers as inexperienced but open to receiving information (Deal et al., 2010; Nadler et al., 2017; North \& Fiske, 2012).

In addition, the results indicated that trustworthiness moderated the relationships between age and perceived ability and motivation to share knowledge, in a way that information about someone's trustworthiness did not only change the strength of the age effects as anticipated, but also the direction of the age effects. We had expected that high trustworthiness would override age effects by buffering the positive effect of age on perceived ability and motivation to share knowledge, and the negative effect of age on perceived ability and motivation to receive knowledge. However, high trustworthiness only buffered the negative effect of age on perceived ability to receive knowledge, while it changed the nature of the relationships for the other three effects. Specifically, the results suggest that high trustworthiness benefitted younger workers (and therefore penalized older workers) with regard to the perceived motivation to share and to receive knowledge; yet, high trustworthiness benefitted older workers (and therefore penalized younger workers) with regard to the perceived ability to share knowledge. Trustworthiness benefitted both younger and older workers with regard to the perceived ability to receive knowledge in a way that the effect of age is no longer significant when trustworthiness is high (vs. low). Taken together, these findings show the importance of trustworthiness as a relevant contingency for the bidirectional knowledge transfer between older and younger workers.

\section{HYPOTHESES DEVELOPMENT: STUDY 2}

In Study 2, we extend our findings from Study 1 using a dyadic research design to uncover the mechanisms through which age influences the knowledge transfer behaviour of older and younger employees, who interact in age-diverse co-worker dyads (Figure 3). Specifically, we provide additional insights by testing whether the actual knowledge transfer behaviour of an individual is influenced by the age of their colleague, and we 


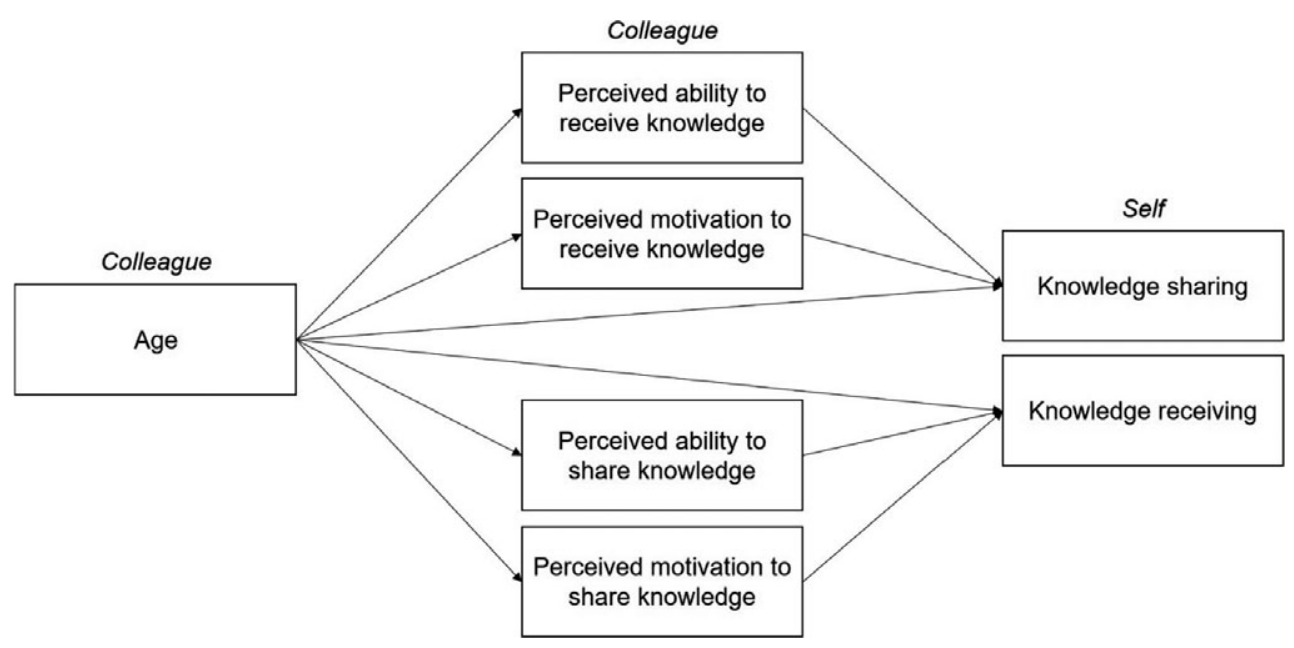

Figure 3. Study 2: Conceptual model.

examine whether this effect can be explained by the perceived ability and motivation of their colleague.

We follow our main argument based on the organizational theory of age effects (Lawrence, 1987) and propose that the age of one's colleague has a positive effect on one's knowledge receiving behaviour and a negative effect on one's knowledge sharing behaviour. This argument is based on the empirical finding that age constitutes a visible and salient demographic characteristic that is automatically assessed in interactions among individuals. In turn, the assessment of someone's age can influence the behaviour towards that interaction partner (Cleveland, Shore, \& Murphy, 1997; Kunze \& Menges, 2016). Based on normative expectations about older workers' wisdom and their willingness to share knowledge resulting from their more pronounced generativity motives (Kooij et al., 2011; Weiss \& Lang, 2012), co-workers should be more open to receiving knowledge from older workers. On the contrary, these normative expectations about older workers' wisdom and generativity might negatively influence employees' knowledge sharing behaviour as they assume that older workers are not interested in receiving knowledge. In addition, negative perceptions about older workers' declining mental capacities (Cuddy et al., 2005), which are necessary to process novel information and knowledge, may further inhibit employees' knowledge sharing behaviour. As a result, we hypothesize that the older the colleague with whom one interacts, the more likely one is to seek and receive knowledge from that colleague, and the less likely one is to share knowledge with that colleague.

Hypothesis 1: The age of one's colleague is negatively associated with one's knowledge sharing.

Hypothesis 2: The age of one's colleague is positively associated with one's knowledge receiving.

In addition, we develop perceived ability and motivation to share and receive knowledge as mediators of the relationship between age and knowledge transfer behaviour. First, age can influence perceptions of one's ability and motivation to complete work-related tasks. On the one hand, older workers, compared to younger workers, are often perceived as less willing to learn and accumulate new knowledge (Karpinska, 
Henkens, \& Schippers, 2013). On the other hand, older workers, compared to younger workers, are more likely to be approached as knowledge senders because they are perceived as capable experts in their field (Dunham \& Burt, 2011). These differential perceptions of the abilities and motivation of older vs. younger workers can also be substantiated by research on mean-level changes in individual characteristics over the work lifespan, which show increases in job knowledge and generativity motives in older workers (Kanfer \& Ackerman, 2004; Kanfer, Beier, \& Ackerman, 2013). Second, research has identified ability and motivation as the most proximal antecedents of knowledge transfer (Reinholt et al., 2011; Siemsen, Roth, \& Balasubramanian, 2008; Wilkesmann et al., 2009), which should also be relevant in the context of age-diverse co-worker dyads (Burmeister \& Deller, 2016). Thus, we hypothesize:

Hypothesis 3: The negative effect of the age of one's colleague on one's knowledge sharing is partially mediated by one's perception of (a) the ability to receive and (b) the motivation to receive knowledge of one's colleague.

Hypothesis 4: The positive effect of the age of one's colleague on one's knowledge receiving is partially mediated by one's perception of (a) the ability to share and (b) the motivation to share knowledge of one's colleague.

\section{Method}

\section{Participants}

The sample consisted of 53 dyads $(N=106)$, and each dyad was composed of an older $(\geq 50$ years) and a younger colleague ( $<35$ years). Based on research on ageing workforces and knowledge transfer, we selected participants according to the following three criteria: (1) age (Kanfer et al., 2013; Kooij \& Van De Voorde, 2011), (2) minimum dyad tenure in terms of collaboration at work of 3 months (Levin \& Cross, 2004), and (3) opportunity to exchange knowledge at work (Levin \& Cross, 2004). The sample had the following characteristics: On average, participants were 45.13 years old $(S D=13.56$, $\min .=27, \max .=64)$. The group of older workers was aged $58.17(S D=3.85)$, and the group of younger workers was aged $32.09(S D=3.18)$. In all, $66.0 \%$ of participants were female, and all participants had graduated from university with a master degree. Of the participants, $9.4 \%$ were in their first year, $79.2 \%$ had no managerial responsibility, and $11.3 \%$ occupied a leadership position. On average, participants had 16.32 years of work experience $(S D=13.37)$. The tenure of the group of older participants was 29.04 years $(S D=5.05)$, and the tenure of the group of younger participants was 3.60 years $(S D=2.37)$.

\section{Procedure}

We collected data in 12 different secondary schools in Germany. We chose to collect data in the educational sector because workforce ageing has been shown to be particularly pronounced with large numbers of older and retiring teachers (OECD, 2013), making it an appropriate context to study phenomena related to ageing and age-diverse workforces. Further, schools are thought to provide a suitable context for studying topics involving human capital, such as informal learning and knowledge sharing (Bednall \& Sanders, 2017; Bednall, Sanders, \& Runhaar, 2014), due to a relatively structured work organization and a rather controlled set of activities (Pil \& Leana, 2009). School representatives helped to identify the age-diverse dyads in their organization. Participants could choose whether 
they preferred to fill in the questionnaires online or via paper. We administered the questionnaires in German, and items not available in German were translated and backtranslated by two bilingual research assistants to ensure equivalence (Brislin, 1970). We matched responses from younger and older colleagues via a random number code that the participants generated. Please see Appendix B for further details on the procedure.

\section{Measures}

If not indicated otherwise, participants provided their responses on a seven-point Likerttype scale $(1=$ totally disagree, $7=$ totally agree $)$. To acknowledge the specific referents in this study, items were adapted in the following ways: The terms employees and colleagues were exchanged for my colleague and my colleague, and the terms others and them were changed into $m e$ and $s / b e$, respectively. To reduce the potential for common method bias, we collected data on independent and dependent variables using two separate questionnaires that were administered with a time-lag of one to two weeks (Podsakoff, MacKenzie, Lee, \& Podsakoff, 2003).

Age (of colleague)

We asked participants to indicate their chronological age in years. We studied the effect of chronological age, rather than any other age concept (e.g., subjective age), because we aimed to understand the effect of age as a visible demographic characteristic that is automatically assessed and affecting people's behaviour towards each other (Cleveland et al., 1997; Kunze \& Menges, 2016). To be able to examine the effect of the age of one's colleague on one's own knowledge transfer behaviour, we created a new variable in which we exchanged the inputs of older and younger dyad members. This type of data entry has been called pairwise data entry and can be used to calculate partner effects in dyadic research (see Kenny, Kashy, \& Cook, 2006 for more details).

\section{Perceived ability to share knowledge (of colleague)}

As in Study 1, we used the five-item scale developed by Burmeister et al. (2017) to measure perceived ability to share knowledge. Participants assessed their colleagues' ability to share knowledge. A sample item is 'My colleague is able to explain the usefulness of his/her knowledge to me'. Cronbach's $\alpha$ was .92.

Perceived motivation to share knowledge (of colleague)

As in Study 1, we used the six-item scale developed by Burmeister et al. (2017) to measure perceived motivation to share knowledge. Participants assessed their colleagues' motivation to share knowledge. A sample item is 'My colleague is not afraid of losing power when transferring his/her knowledge to me'. Cronbach's $\alpha$ was .85.

Perceived ability to receive knowledge (of colleague)

As in Study 1, we used the five-item scale developed by Burmeister et al. (2017) to measure perceived ability to receive knowledge. Participants assessed their colleagues' ability to receive knowledge. A sample item is 'My colleague has the ability to acquire knowledge from me'. Cronbach's $\alpha$ was .91. 
Perceived motivation to receive knowledge (of colleague)

As in Study 1, we used the six-item scale developed by Burmeister et al. (2017) to measure perceived motivation to receive knowledge. Participants assessed their colleagues' motivation to receive knowledge. A sample item is 'My co-worker actively seeks out knowledge from me'. Cronbach's $\alpha$ was .83.

\section{Knowledge sharing}

Knowledge sharing was measured by the three-item scale developed by Wilkesmann $e t$ al. (2009). A sample item is 'I show my colleague special procedures so that he/she can learn them'. Cronbach's $\alpha$ was .87 .

\section{Knowledge receiving}

Knowledge receiving was measured by the four-item scale developed by Wilkesmann et al. (2009). A sample item is 'I learn a lot by asking my colleague'. Cronbach's $\alpha$ was .91.

\section{Data analysis}

Calculation of ICC1 showed that $23.2 \%$ of the variance in knowledge sharing and $17.1 \%$ of the variance in knowledge receiving was attributable to the dyad level. We acknowledged the non-independence of our data (i.e., individuals nested within dyads) using hierarchical linear modelling (Klein \& Kozlowski, 2000) to obtain the regression coefficients. For example, we tested how the age of the younger colleague affected the knowledge transfer behaviour of the older colleague, and how the age of the older colleague affected the knowledge transfer behaviour of the younger colleague, while controlling for the dyadic interdependence of their data. Following Kenny et al. (2006), we grand-mean-centred the predictor variables.

All analyses were performed in $\mathrm{R}$ version 3.2.3 using the package lmer (R Core Team, 2015). To test the significance of the hypothesized indirect effects, we used the Monte Carlo method by creating 95 per cent confidence intervals (CIs) with 20,000 replications (Preacher, Zyphur, \& Zhang, 2010). The Monte Carlo confidence interval method is useful because it does not assume a normal distribution but simulates the sampling distribution from the model estimates and their asymptotic variances (Bauer, Preacher, \& Gil, 2006; Preacher \& Selig, 2012).

\section{Results}

Table 3 presents the mean scores, standard deviations, and intercorrelations of the studied variables. The results for hypotheses testing are presented in Table 4. According to Table 4, Hypothesis 1 was supported because the age of one's colleague was negatively associated with one's knowledge sharing $(r=-.06, p<.01){ }^{2}$. Similarly, Hypothesis 2 , which stated that the age of one's colleague is positively associated with one's knowledge receiving, was supported $(r=.05, p<.01)$.

\footnotetext{
${ }^{2}$ We also tested for nonlinear relationships between age and knowledge sharing, knowledge receiving, ability and motivation to share, and ability and motivation to receive knowledge. We found one curvilinear relationship between colleague's age and one's own knowledge sharing behaviour $(\mathrm{r}=.003, \mathrm{t}=2.32, \mathrm{p}<.05)$. As beyond the scope of our manuscript, future research should investigate potential nonlinear relationships.
} 
Table 3. Study 2. Means, standard deviations, intercorrelations, and Cronbach's $\alpha$

\begin{tabular}{|c|c|c|c|c|c|c|c|c|c|}
\hline Variable & M & $S D$ & I & 2 & 3 & 4 & 5 & 6 & 7 \\
\hline I. Age of other colleague & 45.13 & 13.56 & $(-)$ & & & & & & \\
\hline $\begin{array}{l}\text { 2. Perceived ability } \\
\text { to share knowledge }\end{array}$ & 5.72 & 1.05 & .18 & $(.92)$ & & & & & \\
\hline $\begin{array}{l}\text { 3. Perceived motivation } \\
\text { to share knowledge }\end{array}$ & 5.64 & 0.95 & $.36^{* *}$ & $.56^{* *}$ & $(.85)$ & & & & \\
\hline $\begin{array}{l}\text { 4. Perceived ability to } \\
\text { receive knowledge }\end{array}$ & 5.64 & 1.05 & $-.23 *$ & $.63^{* *}$ & .19 & $(.91)$ & & & \\
\hline $\begin{array}{l}\text { 5. Perceived motivation } \\
\text { to receive knowledge }\end{array}$ & 5.97 & 1.00 & -.02 & $.32^{* *}$ & $.31^{* *}$ & $.39 * *$ & $(.83)$ & & \\
\hline $\begin{array}{l}\text { 6. Knowledge sharing } \\
\text { behaviour }\end{array}$ & 4.48 & 1.52 & $-.53^{* *}$ & -.15 & -.12 & $.33^{*}$ & $.21^{*}$ & $(.87)$ & \\
\hline $\begin{array}{l}\text { 7. Knowledge receiving } \\
\text { behaviour }\end{array}$ & 5.24 & 1.31 & $.53^{* *}$ & $.5 I^{* *}$ & $.50 * *$ & .17 & $.22 *$ & -.10 & $(.91)$ \\
\hline
\end{tabular}

Notes.. $N=53$ dyads (106 individuals). Cronbach's $\alpha$ on diagonal. Response scales for variables 2 . to 7 . ranged from I to 7 .

$*_{p}<.05$.

$* * p<.01$.

In the next step, to examine Hypothesis 3, we examined whether perceived ability to receive and perceived motivation to receive knowledge mediated the effect of one's colleague's age on one's knowledge sharing behaviour. The first estimated indirect effect through perceived ability to receive was -0.01 with a $95 \%$ CI of $[-0.01,-0.00]$, supporting Hypothesis $3 \mathrm{a}$ and suggesting that age of one's colleague promoted one's knowledge sharing behaviour through perceived ability to receive. However, the second estimated indirect effect through perceived motivation to receive was -0.00 with a $95 \%$ $\mathrm{CI}$ of $[-0.00,0.00]$. As zero was included in the Monte Carlo confidence interval, our data did not support Hypothesis $3 b$.

To examine Hypothesis 4, we tested whether perceived ability to share and perceived motivation to share knowledge mediated the effect of one's colleague's age on one's knowledge receiving behaviour. The first estimated indirect effect through perceived ability to share was .01 with a $95 \%$ CI of $[-0.00,0.00]$. As zero was included in the confidence interval, Hypothesis 4 a was not supported. However, we found support for Hypothesis $4 \mathrm{~b}$ because perceived motivation to share knowledge mediated the effect of age of one's colleague on one's knowledge receiving (indirect effect $=0.01,95 \%$ CI $[0.01$, $0.02])$.

\section{GENERAL DISCUSSION}

In this multistudy investigation, we shed light on the relationship between age and knowledge transfer in organizations. In line with our predictions that we derived from the organizational theory of age effects (Lawrence, 1987), we found that age is positively associated with being perceived as a knowledge sender and negatively associated with being perceived as a knowledge recipient. Further, our findings indicate that perceived ability and motivation mediate the effects of the age of one's colleague on one's own knowledge sharing and receiving behaviour. Finally, based on the results of Study 1, we 


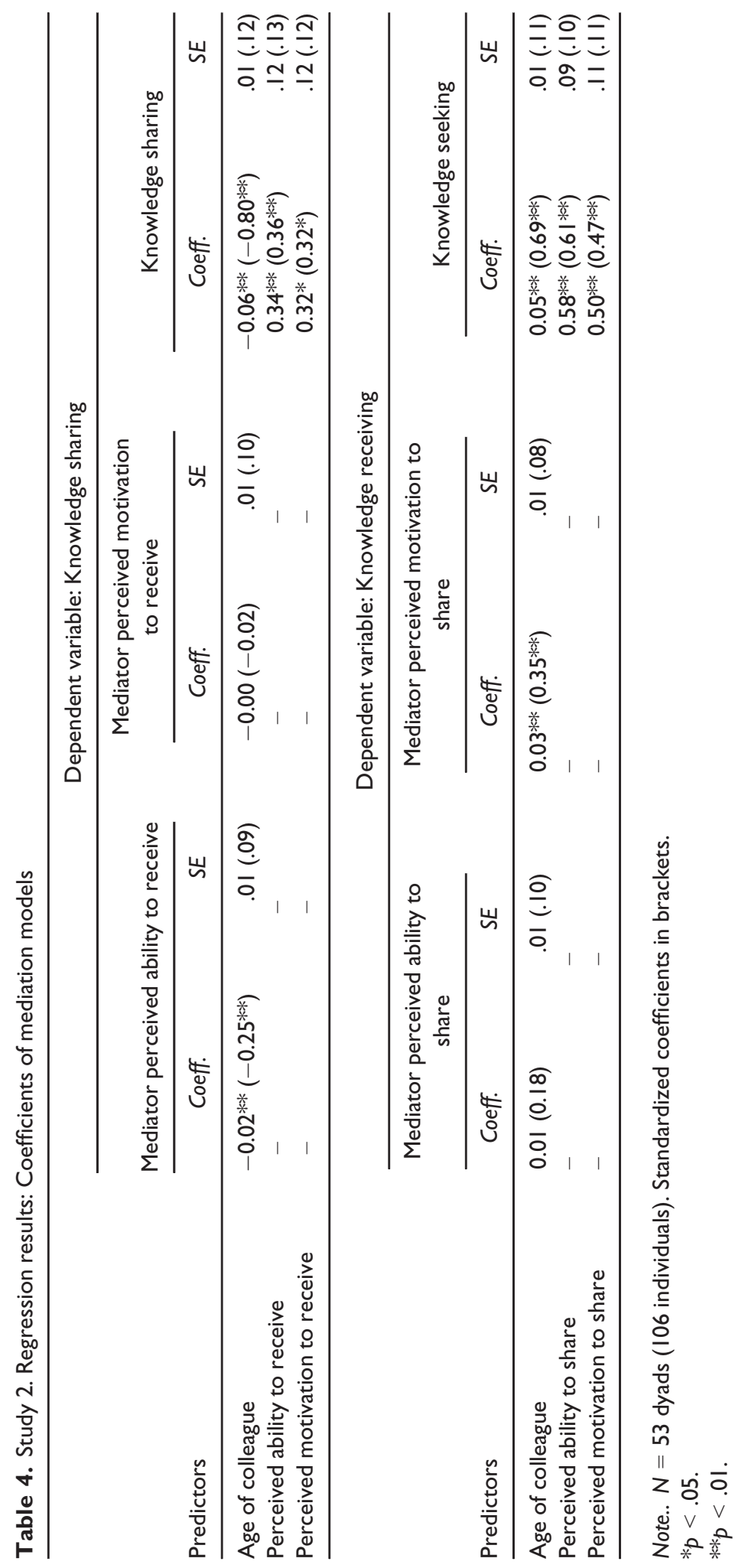


found some support for the notion that trustworthiness can buffer the effects of age on knowledge receiving and sharing perceptions.

\section{Theoretical implications}

Our findings have four theoretical implications. First, our findings suggest that predictions made by the organizational theory of age effects (Lawrence, 1987) can be applied to the context of knowledge transfer in organizations, thus broadening the scope of application of the theory. As such, age seems to elicit normative expectations concerning the roles that individuals are to occupy in knowledge transfer processes. Accordingly, employees tend to associate older workers with the role of knowledge senders, and younger workers with the role of knowledge receivers. More specifically, rather than being the go-to people for knowledge sharing as suggested by previous research (Dunham \& Burt, 2011), older workers seem to be perceived as employees who see themselves as the go-to people, based on their willingness to share knowledge with younger colleagues. Thus, including age as an important antecedent in models of knowledge transfer seems to be important because workforces are becoming ever more age diverse (Shultz \& Adams, 2007), and predictions of knowledge transfer behaviour may be incorrect when age effects are ignored. The importance of the role of age in knowledge transfer is amplified by the notion that age, as a salient individual characteristic, is automatically assessed and results in alterations of one's behaviour towards interaction partners (Cleveland et al., 1997; Kunze \& Menges, 2016).

Second, we contribute to research on the organizational theory of age effects with regard to mediating mechanisms (here: perceived ability and motivation) that explain how age elicits its effect on knowledge sharing and receiving behaviour in organizations. Our findings suggest that, in age-diverse co-worker dyads, perceived ability to receive knowledge explains the negative effect of the age of one's colleague on knowledge sharing, while perceived motivation to share knowledge explains the positive effect of the age of one's colleague on knowledge receiving. These findings complement studies that have shown that motives can explain the differential work behaviour of older and younger employees (Kooij \& Van De Voorde, 2011; Krumm, Grube, \& Hertel, 2013), by proposing a motivational and an ability-related mechanism to explain the effects on knowledge transfer, as a specific work behaviour.

Third, we shed light on the moderating role of trustworthiness on the relationship between age and knowledge transfer. Our findings reveal that high trustworthiness can buffer the effect of age on prescribed roles in knowledge transfer. In situations of insufficient knowledge about others' trustworthiness, people tend to use other information, such as age, as cues to understand whether colleagues are able and motivated to share or receive knowledge at work relying on implicit age norms (Phillips \& Loyd, 2006). However, our results indicate that information about someone's trustworthiness can override implicit age norms and role expectations associated with knowledge transfer behaviour. Specifically, our results showed that high trustworthiness benefitted older workers with regard to the perceived ability to share knowledge. Yet, high trustworthiness penalized them (and benefitted younger workers instead) with regard to the perceived motivation to share and to receive knowledge. Results further showed that both younger and older workers benefitted from trustworthiness with regard to the perceived ability to receive knowledge in a way that the effect of age is no longer significant when trustworthiness is high (vs. low). Together, these findings support the notion that trustworthiness can reduce the risks associated with sharing and receiving 
knowledge, such as admitting knowledge gaps and being perceived as less knowledgeable by colleagues (Bender \& Fish, 2000; Borgatti \& Cross, 2003). Overall, this supports the role of trustworthiness as an important contingency for the bidirectional knowledge transfer between older and younger workers.

Fourth, we were able to uncover the relationships between age and knowledge transfer behaviour, based on the distinction we made between the two constituting parts of the knowledge transfer construct: knowledge sharing and knowledge receiving. On a conceptual level, researchers have made this distinction for decades, but it has seldom been applied in empirical studies (Davenport \& Prusak, 1998; Schmidt \& Muehlfeld, 2017; Tsai, 2001; Wilkesmann et al., 2009). Our findings emphasize that the distinction between knowledge sharing and knowledge receiving is critical because the use of a composite knowledge transfer construct would mask the differential effects of age on knowledge sharing and knowledge receiving. Thus, our findings show that certain antecedents can only be identified if knowledge sharing and knowledge receiving are studied as two related, but distinct, dimensions of knowledge transfer behaviour.

\section{Limitations and future research directions}

Like every study, our study is not without limitations. First, the characteristics of our samples might limit the generalizability of our findings. We collected data for both studies from German employees, which might limit the cross-cultural generalizability of our findings. For example, Germany is thought to have a highly individualistic culture (Hofstede, Hofstede, \& Minkov, 2010). Individuals from more collectivistic cultures might engage in more intense knowledge sharing among in-group members, but less knowledge sharing among outgroup members (Michailova \& Hutchings, 2006), which might affect knowledge sharing between younger and older employees. In addition, we obtained data for Study 2 from matched pairs of teachers. The educational sector might be different from non-educational industries, for example, in terms of organizational structures and individuals' autonomy in how to perform their work (Bednall \& Sanders, 2017). Thus, future studies need to establish the cross-cultural generalizability of our results and the generalizability of the findings of Study 2 to non-educational industries. Second, our manipulation of the trustworthiness dimension in Study 1 worked only in part, which implied that we were not able to investigate to what extent the three dimensions of trustworthiness influence perceived ability and motivation to share and receive knowledge. Previous research revealed that the three dimensions are highly correlated with each other and interact to predict trust (e.g., Colquitt et al., 2007; Mayer \& Gavin, 2005; Poon, 2013), suggesting that it is difficult to tear them apart in experimental research. From the eye of the participant, it appears to be challenging to distinguish among the three dimensions of trustworthiness based on verbal descriptions of employees. Future research could try to disentangle the effects of the three trustworthiness dimensions using more elaborate study materials, such as audio or video messages, to depict someone's competence, benevolence, and integrity.

Our findings provide several additional directions for future research. First, future research needs to clarify the inconsistent relationship between age and perceived ability to share knowledge because we found a significant, negative relationship in Study 1 and a positive, non-significant relationship in Study 2. The potential negative relationship might be explained by persisting age stereotypes about older individuals as warm but incompetent (Cuddy et al., 2005). Even though these age stereotypes that associate older workers with performance decreases do not correspond with empirical evidence 
(Hertel \& Zacher, 2015), they might negatively affect the perception of older workers' ability to share knowledge. Future research could investigate whether age stereotypes explain the relationship between age and perceived ability to share knowledge. Further, researchers could test the effect of different contextual boundary conditions that might explain the identified inconsistency.

Second, future studies should explore contextual boundary conditions of the effect of age on one's knowledge transfer behaviour. For example, it seems worthwhile to examine how organizational practices aimed at creating a positive work atmosphere for workers from all age groups, such as age-inclusive HR practices and age-diversity climates (Boehm, Kunze, \& Bruch, 2014; Fasbender \& Wang, 2017; Iweins, Desmette, Yzerbyt, \& Stinglhamber, 2013; King \& Bryant, 2017), influence the effect of age on knowledge sharing and knowledge-seeking behaviour. We would expect that age-inclusive HR practices might be able to buffer or even change the nature of the relationship between age and knowledge transfer.

Third, researchers need to broaden our focus on age by examining the relationship between alternative age-related constructs and other predictors of knowledge transfer behaviour in organizations. We know that several other age-related constructs, such as subjective age, affect the behaviour of individuals at work (Kooij, de Lange, Jansen, \& Dikkers, 2013; Kunze, Raes, \& Bruch, 2015). Researchers who use alternative age constructs could contribute a more nuanced understanding of the relationship between age and knowledge transfer, and help to disentangle age effects from effects of related, but distinct, constructs (e.g., experience). In addition, knowledge transfer is influenced by a variety of other predictors, including individual, relational, contextual, and knowledge characteristics (Szulanski, 1996), which still have to be examined in the context of knowledge transfer among employees from different age groups (Burmeister \& Deller, 2016). Some of these factors might be particularly relevant. For example, research has suggested that older and younger employees have different types of knowledge (Gerpott et al., 2017), and it would be useful to understand how these knowledge types affect the knowledge transfer process. Researchers could examine whether the motivation to share and receive knowledge is dependent on knowledge types (e.g., job knowledge, social knowledge, political knowledge), and whether the preferred knowledge types differ between older and younger employees.

Fourth, researchers can complement the current study by drawing on the growing literature on the influence of generational identities on intergenerational interactions at work (Joshi, Dencker, Franz, \& Martocchio, 2010; Lyons \& Schweitzer, 2017; Rudolph \& Zacher, 2017). The simplistic use of the generational concept (Mannheim, 1927/1952), in terms of arbitrarily defined age brackets that are said to unify individuals with regard to their beliefs, attitudes, values, and behaviour at work based on shared life experiences during the formative years of their youth, is eschewed by most researchers (Costanza \& Finkelstein, 2015; Rudolph \& Zacher, 2017). However, social identity-based approaches can provide a novel lens to understanding intergenerational interactions, such as knowledge transfer, at work. These novel approaches emphasize that individuals are not passive receivers of the influence of their generational membership, but that the meaningfulness of their generational identity is shaped by their degree of identification and the emotional significance of their group membership (Joshi et al., 2010; Lyons \& Schweitzer, 2017). Future research could integrate this idea by testing how generational identification influences the relationship between age and knowledge transfer, and whether generational identity explains variance in knowledge transfer above and beyond age. 


\section{Practical implications}

The current investigation offers relevant implications for organizations that wish to facilitate knowledge transfer between age-diverse colleagues. Organizations that are interested in using the full potential inherent in bidirectional knowledge flows between older and younger workers can address the identified effects of age norms in several ways. First, the finding that older workers are expected to contribute their knowledge, but might not be considered appropriate knowledge recipients by their colleagues, might have detrimental effects on older workers' perceived developmental opportunities. As these opportunities have been shown to be important for many older workers who wish to develop their knowledge and skills until retirement (Armstrong-Stassen \& Stassen, 2013; Van Vianen, Dalhoeven, \& de De Pater, 2011), organizations should be careful not to disregard older workers when creating opportunities for development. Second, organizations can offer awareness trainings in which employees reflect on the age norms that guide their knowledge transfer behaviour at work. Such awareness can facilitate openness to interactions that are seemingly not in line with age norms, such as younger colleagues sharing knowledge with older workers. As a result of the reflection on one's age norms, older workers might be more likely to ask for others' knowledge, and younger workers might be more likely to share their valuable knowledge with colleagues despite their limited experience. Third, organizations can offer trainings that influence individuals' ability and motivation to engage in knowledge transfer. Trainings that clarify the positive effects of knowledge transfer for the individual (e.g., recognition) and the organization (e.g., performance) can positively influence motivation. Trainings that offer advice on how to identify one's own valuable knowledge, and how to communicate this knowledge effectively to others, can positively influence ability. Fourth, our finding that trustworthiness can play a relevant role should be reflected in organizational practices that facilitate positive interactions among employees of different age groups. For example, organizations can emphasize through means of internal communication (e.g., newsletter, company magazine) that employees from different age groups are not competing for resources, because such narratives have been shown to positively influence perceptions of individuals from the other age group (North \& Fiske, 2015). Furthermore, organizations can provide intergenerational contact opportunities (Henry et al., 2015), through agediverse projects teams, open work spaces, and social events. Such positive contact between employees of different age groups could, in turn, provide opportunities to develop more favourable assessments of each other's trustworthiness, thereby positively affecting knowledge between age-diverse co-workers.

\section{Acknowledgements}

We thank Anna Maaß for her support in collecting the data for Study 2.

\section{References}

Aguinis, H., \& Bradley, K. J. (2014). Best practice recommendations for designing and implementing experimental vignette methodology studies. Organizational Research Methods, 17(4), 351371. https://doi.org/10.1177/1094428114547952

Aguinis, H., Gottfredson, R. K., \& Culpepper, S. A. (2013). Best-practice recommendations for estimating cross-level interaction effects using multilevel modeling. Journal of Management, 39, 1490-1528. https://doi.org/10.1177/0149206313478188 
Andrews, K. M., \& Delahaye, B. L. (2000). Influences on knowledge processes in organizational learning: The psychosocial filter. Journal of Management Studies, 37, 797-810. https://doi. org/10.1111/1467-6486.00204

Armstrong-Stassen, M., \& Stassen, K. (2013). Professional development, target-specific satisfaction, and older nurse retention. Career Development International, 18(7), 673-693. https://doi.org/ 10.1108/CDI-08-2013-0102

Bauer, D. J., Preacher, K. J., \& Gil, K. M. (2006). Conceptualizing and testing random indirect effects and moderated mediation in multilevel models: New procedures and recommendations. Psychological Methods, 11(2), 142-163. https://doi.org/10.1037/1082-989X.11.2.142

Bednall, T. C., \& Sanders, K. (2017). Do opportunities for formal learning stimulate follow-up participation in informal learning: A three-wave study. Human Resource Management, 56, 803-820. https://doi.org/10.1002/hrm.21800

Bednall, T. C., Sanders, K., \& Runhaar, P. (2014). Stimulating informal learning activities through perceptions of performance appraisal quality and human resource management system strength: A two-wave study. Academy of Management Learning E Education, 13(1), 45-61. https://doi.org/10.5465/amle.2012.0162

Bender, S., \& Fish, A. (2000). The transfer of knowledge and the retention of expertise: The continuing need for global assignments. Journal of Knowledge Management, 4(2), 125-137. https://doi.org/10.1108/13673270010372251

Boehm, S. A., Kunze, F., \& Bruch, H. (2014). Spotlight on age-diversity climate: The impact of ageinclusive HR practices on firm-level outcomes. Personnel Psychology, 67, 667-704. https://doi. org/10.1111/peps. 12047

Borgatti, S. P., \& Cross, R. (2003). A relational view of information seeking and learning in social networks. Management Science, 49(4), 432-445. https://doi.org/10.1287/mnsc.49.4.432. 14428

Brislin, R. W. (1970). Back-translation for cross-cultural research. Journal of Cross-Cultural Psychology, 1, 185-216. https://doi.org/10.1177/135910457000100301

Burmeister, A., \& Deller, J. (2016). Knowledge retention from older and retiring workers: What do we know, and where do we go from here? Work, Aging and Retirement, 2, 87-104. https://doi. org/10.1093/workar/waw002

Burmeister, A., Lazarova, M. B., \& Deller, J. (2017). It takes two to tango: Antecedents of repatriate knowledge transfer. Manuscript submitted for publication.

Cleveland, J. N., Shore, L. M., \& Murphy, K. R. (1997). Person- and context-oriented perceptual age measures: Additional evidence of distinctiveness and usefulness. Journal of Organizational Behavior, 18(3), 239-251. https://doi.org/10.1002/(ISSN)1099-1379

Colquitt, J. A., Scott, B. A., \& LePine, J. A. (2007). Trust, trustworthiness, and trust propensity: A meta-analytic test of their unique relationships with risk taking and job performance. The Journal of applied psychology, 92, 909-927. https://doi.org/10.1037/0021-9010.92.4. 909

Costanza, D. P., \& Finkelstein, L. M. (2015). Generationally based differences in the workplace: Is there a there there? Industrial and Organizational Psychology, 8(3), 308-323. https://doi.org/ $10.1017 /$ iop. 2015.15

Cuddy, A. J. C., Norton, M. I., \& Fiske, S. T. (2005). This old stereotype: The pervasiveness and persistence of the elderly stereotype. Journal of Social Issues, 61(2), 267-285. https://doi.org/ $10.1111 /$ j.1540-4560.2005.00405.x

Davenport, T. H., \& Prusak, L. (1998). Working knowledge: How organizations manage what they know. Boston, MA: Harvard Business School Press. https://doi.org/10.1145/348772.348775

Deal, J. J., Altman, D. G., \& Rogelberg, S. G. (2010). Millennials at work: What we know and what we need to do (if anything). Journal of Business and Psychology, 25(2), 191-199. https://doi.org/ 10.1007/s10869-010-9177-2

Dunham, A. H., \& Burt, C. D. (2011). Organizational memory and empowerment. Journal of Knowledge Management, 15, 851-868. https://doi.org/10.1108/13673271111174366

Erikson, E. H. (1963). Childhood and society. New York, NY: Norton. 
Fasbender, U., \& Wang, M. (2017). Negative attitudes toward older workers and hiring decisions: Testing the moderating role of decision makers' core self-evaluations. Frontiers in Psychology, 7, 1-10. https://doi.org/10.3389/fpsyg.2016.02057

Finkelstein, L. M., Allen, T. D., \& Rhoton, L. A. (2003). An examination of the role of age in mentoring relationships. Group \& Organization Management, 28(2), 249-281. https://doi.org/10.1177/ 1059601103251230

Finkelstein, L. M., Kulas, J. T., \& Dages, K. D. (2003). Age differences in proactive newcomer socialization strategies in two populations. Journal of Business and Psychology, 17(4), 473502. https://doi.org/10.1023/A:1023400201387

German Federal Statistics Office. (2016). Labor market statistics. Retrieved from https://www. destatis.de/DE/Publikationen/StatistischesJahrbuch/Arbeitsmarkt.pdf?_blob=publicationFile

Gerpott, F. H., Lehmann-Willenbrock, N., \& Voelpel, S. (2017). A phase model of intergenerational learning in organizations. Academy of Management Learning \& Education, 16(2), 193-216. https://doi.org/10.5465/amle.2015.0185

Harvey, J. (2012). Managing organizational memory with intergenerational knowledge transfer. Journal of Knowledge Management, 16, 400-417. https://doi.org/10.1108/ 13673271211238733

Heckhausen, J., \& Krueger, J. (1993). Developmental expectations for the self and most other people: Age grading in three functions of social comparison. Developmental Psychology, 29, 539-548. https://doi.org/10.1037//0012-1649.29.3.539

Henry, H., Zacher, H., \& Desmette, D. (2015). Reducing age bias and turnover intentions by enhancing intergenerational contact quality in the workplace: The role of opportunities for generativity and development. Work, Aging and Retirement, 1(3), 243-253. https://doi.org/10. 1093/workar/wav005

Hertel, G., \& Zacher, H. (2015). Managing the aging workforce. In C. Viswesvaran, N. Anderson, D. S. Ones \& H. K. Sinangil (Eds.), The SAGE handbook of industrial, work, \& organizational psychology (pp. 396-428). New York, NY: Sage.

Hofstede, G., Hofstede, G. J., \& Minkov, M. (2010). Cultures and organizations: Software of the mind (3rd ed.). New York, NY: McGraw-Hill.

Iweins, C., Desmette, D., Yzerbyt, V., \& Stinglhamber, F. (2013). Ageism at work: The impact of intergenerational contact and organizational multi-age perspective. European Journal of Work and Organizational Psychology, 22(3), 331-346. https://doi.org/10.1080/1359432X.2012. 748656

Joshi, A., Dencker, J., Franz, G., \& Martocchio, J. (2010). Unpacking generational identities in organizations. Academy of Management Review, 35(3), 392-414. https://doi.org/10.5465/AMR

Kanfer, R., \& Ackerman, P. L. (2004). Aging, adult development, and work motivation. The Academy of Management Review, 29, 440-458. https://doi.org/10.2307/20159053

Kanfer, R., Beier, M. E., \& Ackerman, P. L. (2013). Goals and motivation related to work in later adulthood: An organizing framework. European Journal of Work and Organizational Psychology, 22(3), 253-264. https://doi.org/10.1080/1359432X.2012.734298

Karpinska, K., Henkens, K., \& Schippers, J. (2013). Hiring retirees: Impact of age norms and stereotypes. Journal of Managerial Psychology, 28(7/8), 886-906. https://doi.org/10.1108/ JMP-07-2013-0223

Kenny, D. A., Kashy, D. A., \& Cook, W. L. (2006). Dyadic data analysis. New York, NY: Guilford Press.

King, S. B., \& Bryant, F. B. (2017). The Workplace Intergenerational Climate Scale (WICS): A selfreport instrument measuring ageism in the workplace. Journal of Organizational Behavior, 38 (1), 124-151. https://doi.org/10.1002/job.2118

Klein, K. J., \& Kozlowski, S. W. (Eds.) (2000). Multilevel theory, research, and methods in organizations. San Francisco, CA: Jossey-Bass.

Kooij, D., de Lange, A. H., Jansen, P., \& Dikkers, J. (2008). Older workers' motivation to continue to work: Five meanings of age: A conceptual review. Journal of Managerial Psychology, 23(4), 364-394. https://doi.org/10.1108/02683940810869015 
Kooij, D., De Lange, A. H., Jansen, P. G., \& Dikkers, J. S. (2013). Beyond chronological age: Examining perceived future time and subjective health as age-related mediators in relation to work-related motivations and well-being. Work \& Stress, 27(1), 88-105. https://doi.org/10.1080/02678373. 2013.769328

Kooij, D. T. A. M., de Lange, A. H., Jansen, P. G. W., Kanfer, R., \& Dikkers, J. S. E. (2011). Age and work-related motives: Results of a meta-analysis. Journal of Organizational Behavior, 32(2), 197-225. https://doi.org/10.1002/job.665

Kooij, D., \& Van De Voorde, K. (2011). How changes in subjective general health predict future time perspective, and development and generativity motives over the lifespan. Journal of Occupational and Organizational Psychology, 84, 228-247. https://doi.org/10.1111/j.20448325.2010.02012.x

Krumm, S., Grube, A., \& Hertel, G. (2013). The Munster work value measure. Journal of Managerial Psychology, 28(5), 532-560. https://doi.org/10.1108/JMP-07-2011-0023

Kunze, F., \& Menges, J. I. (2016). Younger supervisors, older subordinates: An organizational-level study of age differences, emotions, and performance. Journal of Organizational Behavior, 38 (4), 461-486. https://doi.org/10.1002/job

Kunze, F., Raes, A. M. L., \& Bruch, H. (2015). It matters how old you feel: Antecedents and performance consequences of average relative subjective age in organizations. Journal of Applied Psychology, 100, 1511-1526. https://doi.org/10.1037/a0038909

Lawrence, B. S. (1987). An organizational theory of age effects. In S. Bacharach \& N. DiTomaso (Eds.), Research in the sociology of organizations (pp. 37-71). Greenwich, CT: JAI.

Lawrence, B. S. (1988). New wrinkles in the theory of age: Demography, norms, and performance ratings. Academy of Management Journal, 31(2), 309-337. https://doi.org/10. $2307 / 256550$

Levin, D. Z., \& Cross, R. (2004). The strength of weak ties you can trust: The mediating role of trust in effective knowledge transfer. Management Science, 50(11), 1477-1490. https://doi.org/10. $1287 / \mathrm{mnsc} .1030 .0136$

Levin, D. Z., Whitener, E. M., \& Cross, R. (2006). Perceived trustworthiness of knowledge sources: The moderating impact of relationship length. Journal of Applied Psychology, 91, 1163-1171. https://doi.org/10.1037/0021-9010.91.5.1163

Lyons, S. T., \& Schweitzer, L. (2017). A qualitative exploration of generational identity: Making sense of young and old in the context of today's workplace. Work, Aging and Retirement, 3(2), 209224. https://doi.org/10.1093/workar/waw024

Mannheim, K. (1952). The problem of generations. In P. Kecskemeti (Ed.), Essays in the sociology of knowledge (pp. 276-322). Boston, MA: Routledge \& Kegan Paul. (Original work published 1927)

Martins, E. C., \& Meyer, H. W. (2012). Organizational and behavioral factors that influence knowledge retention. Journal of Knowledge Management, 16(1), 77-96. https://doi.org/10. $1108 / 13673271211198954$

Mayer, R. C., Davis, J. H., \& Schoorman, F. D. (1995). An integrative model of organizational trust. The Academy of Management Review, 20, 709-734. https://doi.org/10.2307/258792

Mayer, R. C., \& Gavin, M. B. (2005). Trust in management and performance: Who minds the shop while the employees watch the boss? Academy of Management Journal, 48, 874-888. https:// doi.org/10.5465/AMJ.2005.18803928

McGregor, J. (2001). Employment of the older worker. Palmerston North, New Zealand: Massey University.

Michailova, S., \& Hutchings, K. (2006). National cultural influences on knowledge sharing: A comparison of China and Russia. Journal of Management Studies, 43(3), 383-405. https://doi. org/10.1111/j.1467-6486.2006.00595.x

Muthén, L. K., \& Muthén, B. O. (2015). Mplus user's guide. Los Angeles, CA: Author.

Nadler, J. T., Morr, R., \& Naumann, S. (2017). Millennials, media, and research: Ageism and the younger worker. In E. Parry \& J. McCarthy (Eds.), The Palgrave handbook of age 
diversity and work (pp. 423-446). London, UK: Palgrave. https://doi.org/10.1057/978-1137-46781-2

North, M. S., \& Fiske, S. T. (2012). An inconvenienced youth? Ageism and its potential intergenerational roots. Psychological Bulletin, 138, 982-997. https://doi.org/10.1037/ a0027843

North, M. S., \& Fiske, S. T. (2015). Intergenerational resource tensions in the workplace and beyond: Individual, interpersonal, institutional, international. Research in Organizational Behavior, 35(1), 159-179. https://doi.org/10.1016/j.riob.2015.10.003

OECD. (2013). Education policy outlook: Germany. Retrieved from http://www.oecd.org/edu/ EDUCATIONPOLICY OUTLOOK GERMANY_EN.pdf

Phillips, K. W., \& Loyd, D. L. (2006). When surface and deep-level diversity collide: The effects on dissenting group members. Organizational Behavior and Human Decision Processes, 99(2), 143-160. https://doi.org/10.1016/j.obhdp.2005.12.001

Pil, F. K., \& Leana, C. (2009). Applying organizational research to public school reform: The effects of teacher human and social capital on student performance. Academy of Management Journal, 52, 1101-1124. https://doi.org/10.5465/AMJ.2009.47084647

Pinjani, P., \& Palvia, P. (2013). Trust and knowledge sharing in diverse global virtual teams. Information \& Management, 50, 144-153. https://doi.org/10.1016/j.im.2012.10.002

Podsakoff, P. M., MacKenzie, S. M., Lee, J., \& Podsakoff, N. P. (2003). Common method variance in behavioral research: A critical review of the literature and recommended remedies. Journal of Applied Psychology, 88, 879-903. https://doi.org/10.1037/0021-9010. 88.5.879

Poon, J. M. (2013). Effects of benevolence, integrity, and ability on trust-in-supervisor. Employee Relations, 35(4), 396-407. https://doi.org/10.1108/ER-03-2012-0025

Preacher, K. J., \& Selig, J. P. (2012). Advantages of Monte Carlo confidence intervals for indirect effects. Communication Methods and Measures, 6, 77-98. https://doi.org/10.1080/19312458. 2012.679848

Preacher, K. J., Zyphur, M. J., \& Zhang, Z. (2010). A general multilevel SEM framework for assessing multilevel mediation. Psychological Methods, 15(3), 209-233. https://doi.org/10.1037/ a0020141

R Core Team (2015). R: A language and environment for statistical computing. Vienna, Austria: R Foundation for Statistical Computing.

Reinholt, M., Pedersen, T., \& Foss, N. J. (2011). Why a central network position isn't enough: The role of motivation and ability for knowledge sharing in employee networks. Academy of Management Journal, 54, 1277-1297. https://doi.org/10.5465/amj.2009.0007

Rudolph, C. W., \& Zacher, H. (2015). Intergenerational perceptions and conflicts in multi-age and multigenerational environments. In F. Fraccaroli, D. M. Truxillo, L. M. Finkelstein \& R. Kanfer (Eds.), Facing the challenges of a multi-age workforce: A use-inspired approach (pp. 253-282). New York, NY: Routledge. https://doi.org/10.4324/9780203776322

Rudolph, C. W., \& Zacher, H. (2017). Considering generations from a lifespan developmental perspective. Work, Aging and Retirement, 3(2), 113-129. https://doi.org/10.1093/workar/ waw019

Schmidt, X., \& Muehlfeld, K. S. (2017, August). It's just a matter of perspective? Paper presented at 77 th meeting of the Academy of Management, Atlanta, GA.

Schriesheim, C. A., Powers, K. J., Scandura, T. A., Gardiner, C. C., \& Lankau, M. J. (1993). Improving construct measurement in management research: Comments and a quantitative approach for assessing the theoretical content adequacy of paper-and-pencil survey-type instruments. Journal of Management, 19(2), 385-417. https://doi.org/10.1177/014920639301900208

Shultz, K. S., \& Adams, G. A. (2007). Aging and work in the 21st century. London, UK: Lawrence Erlbaum Associates. https://doi.org/10.1080/01924780902718376

Siemsen, E., Roth, A., \& Balasubramanian, S. (2008). How motivation, opportunity, and ability drive knowledge sharing: The constraining-factor model.Journal of Operations Management, 26(3), 426-445. https://doi.org/10.1016/j.jom.2007.09.001 
Staudinger, U. M. (2015). Images of aging: Outside and inside perspectives. Annual Review of Gerontology and Geriatrics, 35(1), 187-209. https://doi.org/10.1891/0198-8794.35.187

Szulanski, G. (1996). Exploring internal stickiness: Impediments to the transfer of best practice within the firm. Strategic Management Journal, 17(S2), 27-43. https://doi.org/10.1002/smj. 4250171105

Szulanski, G., Cappetta, R., \& Jensen, R. J. (2004). When and how trustworthiness matters: Knowledge transfer and the moderating effect of causal ambiguity. Organization Science, 15(5), 600-613. https://doi.org/10.1287/orsc.1040.0096

Tempest, S. (2003). Intergenerational learning: A reciprocal knowledge development process that challenges the language of learning. Management Learning, 34(2), 181-200. https://doi.org/ $10.1177 / 1350507603034002002$

Tews, M. J., Stafford, K., \& Zhu, J. (2009). Beauty revisited: The impact of attractiveness, ability, and personality in the assessment of employment suitability. International Journal of Selection and Assessment, 17(1), 92-100. https://doi.org/10.1111/j.1468-2389.2009.00454.x

Thielmann, I. (2016). Trust. In V. Zeigler-Hill \& T. K. Shackelford (Eds.), Encyclopedia ofpersonality and individual differences (pp. 1-4). Berlin, Germany: Springer.

Thielmann, I., \& Hilbig, B. E. (2015). Trust: An integrative review from a person-situation perspective. Review of General Psychology, 19(3), 249-277. https://doi.org/10.1037/ gpr0000046

Tsai, W. (2001). Knowledge transfer in intraorganizational networks: Effects of network position and absorptive capacity on business unit innovation and performance. Academy of Management Journal, 44, 996-1004. https://doi.org/10.2307/3069443

van Acker, F., Vermeulen, M., Kreijns, K., Lutgerink, J., \& van Buuren, H. (2014). The role of knowledge sharing self-efficacy in sharing Open Educational Resources. Computers in Human Behavior, 39, 136-144. https://doi.org/10.1016/j.chb.2014.07.006

Van Vianen, A. E. M., Dalhoeven, B. A. G. W., \& de De Pater, I. E. (2011). Aging and training and development willingness: Employee and supervisor mindsets. Journal of Organizational Behavior, 32(2), 226-247. https://doi.org/10.1002/job.685

Voelpel, S., Sauer, A., \& Biemann, T. (2012). Career planning for mid- and late-career workers. In J. W. Hedge \& W. C. Borman (Eds.), The oxford handbook of work and aging (pp. 503-519). Oxford, UK New York, NY: Oxford University Press. https://doi.org/10.1093/oxfordhb/ 9780195385052.013 .0153

Weiss, D., \& Lang, F. R. (2012). "They" are old but "I" feel younger: Age-group dissociation as a selfprotective strategy in old age. Psychology and Aging, 27(1), 153-163. https://doi.org/10.1037/ a0024887

Wheeler, A. R., Shanine, K. K., Leon, M. R., \& Whitman, M. V. (2014). Student-recruited samples in organizational research: A review, analysis, and guidelines for future research. Journal of Occupational and Organizational Psychology, 87(1), 1-26. https://doi.org/10.1111/joop. 12042

Wilkesmann, U., Wilkesmann, M., \& Virgillito, A. (2009). The absence of cooperation is not necessarily deflection: Structural and motivational constraints of knowledge transfer in a social dilemma situation. Organization Studies, 30(10), 1141-1164. https://doi.org/10.1177/ 0170840609344385

Zacher, H. (2015). Successful aging at work. Work, Aging and Retirement, 1(1), 4-25. https://doi. org/10.1093/workar/wau006

Received 19 June 2017; revised version received 4 February 2018 


\section{Appendix A: Study I: Manipulation checks for trustworthiness dimension}

With regard to competence, participants were asked: 'How capable or competent do you think this employee is?' The results of the repeated-measures ANOVA revealed a significant main effect for trustworthiness dimension on competence, competence: $M=4.27, S D=1.31$; benevolence: $M=3.83, S D=1.33$; integrity: $M=4.18, S D=1.39$; $F(2,390)=16.21, p<.01$, as intended. With regard to benevolence, participants were asked: "How benevolent or friendly do you think this employee is?" The results of the repeated-measures ANOVA revealed a significant main effect for trustworthiness dimension on benevolence (competence: $M=3.45, \quad S D=0.54$; benevolence: $M=3.12, S D=0.58$; integrity: $M=3.27, S D=0.58 ; F(2,393)=60.96, p<.01)$, however, not in the intended direction because induced benevolence showed lower scores compared to induced competence and induced integrity. Finally, with regard to integrity, participants were asked: 'How upright or principled do you think this employee is?' The results of the repeated-measures ANOVA revealed a significant main effect for trustworthiness dimension on integrity, competence: $M=3.46, S D=0.57$; benevolence: $M=3.18, S D=0.67$; integrity: $M=3.13, S D=0.63 ; F(2,389)=61.20, p<.01$, again not in the intended direction because induced integrity showed lower scores compared to induced competence.

\section{Appendix B: Study 2: Additional Information on the Procedure}

We conducted a pre-test with four teachers to ensure comprehensibility of the items that are typically applied in a business context. Based on these insights, we revised our instructions and defined the term knowledge in more detail. Participants could choose whether they preferred to fill in the questionnaires online or via paper. An independent samples $t$-test showed that no significant differences existed between the two groups with regard to their scores on the two dependent variables knowledge sharing, $t(102)=-0.84, p=\mathrm{ns}$, and knowledge receiving, $t(102)=-0.06, p=\mathrm{ns}$. 